Scientific Review - Engineering and Environmental Sciences (2019), 28 (3), 465-475

Sci. Rev. Eng. Env. Sci. (2019), 28 (3)

Przegląd Naukowy - Inżynieria i Kształtowanie Środowiska (2019), 28 (3), 465-475

Prz. Nauk. Inż. Kszt. Środ. (2019), 28 (3)

http://iks.pn.sggw.pl

DOI 10.22630/PNIKS.2019.28.3.43

\author{
Marcel PAREDES ${ }^{1}$, Rafaela VITERI ${ }^{2,3}$, Dayana AUQUI ${ }^{1}$, David IDROVO ${ }^{1}$ \\ ${ }^{1}$ National University of Chimborazo, Riobamba \\ ${ }^{2}$ Polytechnic School of Chimborazo, Riobamba \\ ${ }^{3}$ Universidad Politécnica de Madrid, Madrid
}

\title{
Determining $\mathrm{NO}_{2}$ immission levels in a conflicted area: Riobamba, Ecuador
}

Key words: emissions, pedestrian flow, traffic flow, nitrogen oxides, environmental liabilities

\section{Introduction}

The atmosphere is a complex mixture of gases and other substances that provide vital oxygen (Kumar, Tsujimura $\&$ Suzuki, 2018). The atmosphere plays a decisive role in the habitability conditions of the planet, its characteristics are not stable, but depend on the activities developed by the living beings that inhabit the Earth. Since man is spread across the face of the planet there is no activity that does not affect the atmosphere in one way or another (El Morabet, 2019). As cities grow, they begin to suffer a series of environmental problems, including air pollution (Bahmankhah $\&$ Coelho, 2017). Air quality is one of the factors of importance in determining the quality of life index of an urban center. An air of low quality is evidenced by: little well-being, affectations to nature or damage to health (Tang, Chao, Wang $\&$ Chen, 2016). The latter result to be the most important consequence of air pollution in areas with high population density and high presence of productive processes (WHO, 2008). There are several atmospheric constitute that when exceed the permissible limits become pollutants, resulting in a low quality air (Rahmati \& Yousefi, 2013). Carbon monoxide (CO), formed in industrial processes and vehicle emissions, sulfur dioxide $\left(\mathrm{SO}_{2}\right)$, generated in facilities that work with fossil fuels, particulate material (PM), originating in vehicle emissions, industrial processes, energy generation, and nitrogen oxides $\left(\mathrm{NO}_{\mathrm{x}}\right)$, mainly generated by vehicle emissions and fertilizers, are part of these components (Park \& Hwang, 2017). The university population becomes a strategic point of this research, because Riobamba, located in Chimborazo has the two largest universities in the center of the country, there 
are four campuses throughout the city of these study centers, with around 40,000 students. Its main effect is to enter the respiratory tract so the reason for this research is to analyze the concentration of $\mathrm{NO}_{2}$ present in the selected domain, which is a center of great vehicular and pedestrian traffic at different times (Nakashima, Sadanaga, Saito, Hoshi \& Ueno, 2017). It is important to know the mechanisms of formation of this gas to be able to measure them through environmental liabilities (Borge et al., 2015) and with the use of technological tool, such as geographic information systems (GIS) and simulation software (PTV VISSIM - PTV VISWALK) that works with atmospheric components and geographic information system, in such a way that they contribute to the elaboration of a model that allows having a more precise vision of the amount of $\mathrm{NO}_{2}$ present in the study area. This makes it possible to have a specific perception in situ (Nakashima et al., 2017). In addition, the relationship between the excessive growth of vehicle fleet in the city of Riobamba and the impact it is causing on pedestrians, through the interpolation of vehicular and pedestrian data with the gas concentration data measured in the study domain (Mishra \& Goyal, 2014). Specifically, students who enter the Edison Riera Rodríguez campus of the university every day through the main entrance, present an obvious direct exposure to this type of atmospheric gases, which can cause health problems. According to Borge et al. (2016), land transport is framed as an important source of air pollution, contributing to an immediate impact on air quality, mainly in urban areas. Air pol- lution represents an important environmental risk to health. Elevated levels of nitrogen dioxide can irritate the lungs and deteriorate lung function, as well as decrease resistance to respiratory infections (Li, Chyang \& Ni, 2018). The irritation caused by this pollutant is related to an increase in mucus in the upper respiratory tract, which can increase respiratory infections and exacerbate the symptoms of patients with chronic respiratory, asthmatic and allergic diseases (Schraufnagel et al., 2019). In fact, recent scientific studies relate exposure to $\mathrm{NO}_{2}$ with a higher incidence of bronchitis, especially in elderly and immunosuppressed, as well as bronchiolitis in children (Nhung et al., 2018). Taking into account the problems analyzed in terms of the topic of air pollution and highlighting the importance of $\mathrm{NO}_{2}$ emissions, it has become a topic of global interest, mainly due to the negative effects that are generated (Grundström, Hak, Chen, Hallquist \& Pleijel, 2015). Therefore, to show a reference of environmental contamination point in Riobamba is important to implement an investigation that highlights the damage it causes to society and the environment in general.

\section{Material and methods}

The domain was determined from the location of entry and exit routes of vehicular and pedestrian traffic, establishing a study area of $200 \mathrm{~m}^{2}$, in which counts were made on the representative days of the week, during peak traffic hours. In the same way that the vehicle count will define the strategic points to determine the number of people, in the entry and exit of 
the domain, such as areas where the university population usually agglomerates at certain times, including public transport stops (Jaikumar, Shiva Nagendra \& Sivanandan, 2017), the counting in each one of the selected points was carried out simultaneously. PTV VISSIM software jointly with PTV VISWALK, allowed to virtually locate the study domain with all the components that are part of it, such as sidewalks, roads, public transport stops and conflict areas, e.g. zebra crossings and intersections (Park \& Hwang, 2017). For the determination of $\mathrm{NO}_{2}$ concentrations, the methodology of Borge et al. (2015), which establishes the use of triethanolamine (TEA) as an absorbent medium, in such a way that passive can be prepared, the diffusion tubes or passive samplers consist of small plastic tubes containing TEA to absorb $\mathrm{NO}_{2}$ to be measured from the air directly (Glarborg, Miller, Ruscic \& Klippenstein, 2018). They have an opening at both ends and their respective lids, and two stainless steel screens or grilles located at the closed end of the tube impregnated with a base of water or acetone in solution with the absorbent (Villanueva \& Dosal, 2008).

The polypropylene tube has two open ends in such a way that the stainless-steel grids are placed at any of the two ends with the help of a clamp to subsequently apply the TEA (Guo et al., 2016) established that the minimum and ideal exposure time is 6.2 days and should not exceed 4 weeks since the life of the absorber is relatively short, in this case it was decided to expose them for 6 days and $12 \mathrm{~h}$. At an established sampling time of 6 days and $12 \mathrm{~h}$, in the entrance to the east parking of the National
University of Chimborazo (UNACH) in Riobamba, the environmental liabilities were located with a variation of height, located as follows: 2, 2.5 and $3 \mathrm{~m}$. For 6 days and 12 h, 30 environmental liabilities were located on power lines and bars that border the campus, along the domain and its surroundings on Antonio José de Sucre avenue. Once the exposure period had elapsed, environmental liabilities were taken to analyze the samples in the spectrophotometer (Chen, Xie, Ma $\&$ Chen, 2018). Previously, each one of them introduced a volume of the color reagent mixture that allows the nitrites to be revealed and read by the team.

The concentration of ambient $\mathrm{NO}_{2}$ generated from the methodology of Borge et al. (2015), allowed to generate an MS Excel matrix with said data in order to interpret them in GIS by means of maps or models that contain the gas concentration along the area that makes up the study domain. The information generated from the simulations is a software tool for the microscopic and multimodal simulation of traffic PTV VISSIM and PTV VISWALK, could be interpreted by a geographic information software, allowing the assembly of the same on a map of the domain. Thus, facilitating the interpretation of the obtained data.

\section{Results and discussion}

The domain was defined and the entrances and exits of vehicles were identified (Fig. 1). The domain is comprised by the track section of Antonio José de Sucre avenue that crosses in front of the main entrance to the campus. In this way, the experimental vehicular capac- 
ity campaign was allowed to determine the number of vehicles circulating in the study domain. Entrance to the Edison Riera Rodríguez campus of the UNACH allows to appreciate the points considered for vehicular and pedestrian counting (Fig. 1). year. The hours with the highest traffic are in the night time. In both cases, the sedan-type vehicle had the highest incidence (Table 1).

In the second point the schedule with the highest vehicular affluence was from 12:55 to $13: 10$ on Tuesday, $21^{\text {st }}$ Novem-

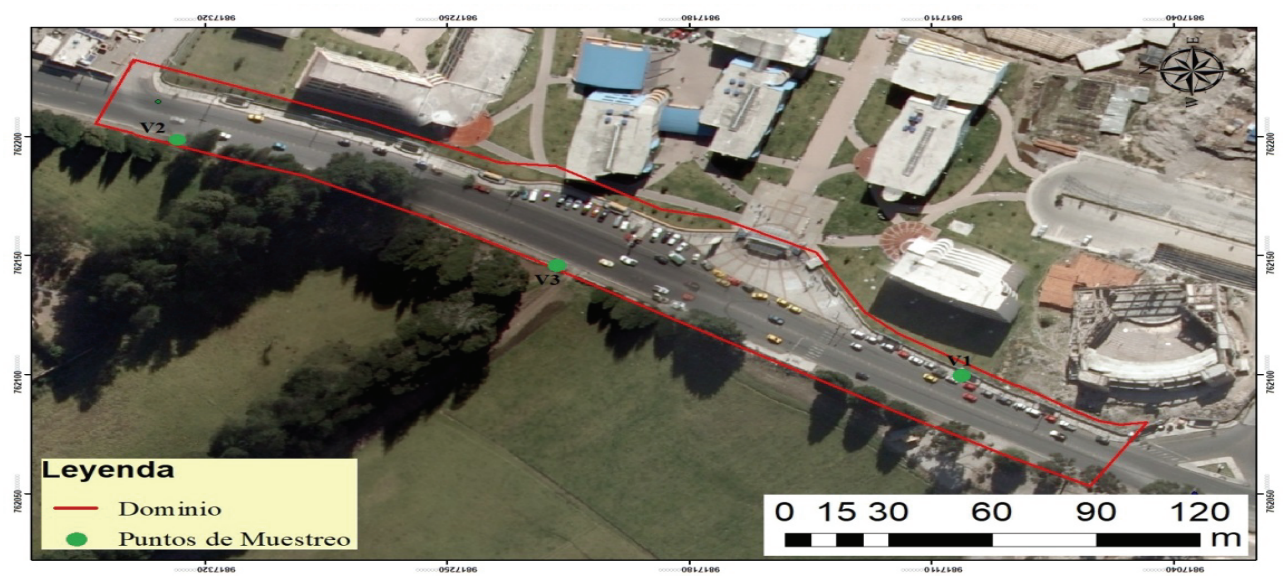

FIGURE 1. Study area and sampling points

When making a comparison referring to the days of vehicle counting, it was obtained that on Tuesday, 21 November of 2018, the hour of greatest vehicular traffic was in the morning hours, while on Saturday, $28^{\text {th }}$ October of the same ber for the departure of students from the university, and from 5:55 to $18: 10$ on Saturday, $28^{\text {th }}$ October, for the vehicles that enter the mall (Kumar et al., 2018), with a presence of more sedan vehicles (Table 2).

TABLE 1. Sampling point 1

\begin{tabular}{|c|c|c|c|c|c|c|}
\hline \multirow{2}{*}{ Vehicle type } & \multicolumn{3}{|c|}{ Tuesday, $21^{\text {st }}$ November } & \multicolumn{3}{c|}{ Saturday, 28 ${ }^{\text {th }}$ October } \\
\cline { 2 - 7 } & $6: 55-7: 10$ & $12: 55-13: 10$ & $17: 55-18: 10$ & $6: 55-7: 10$ & $12: 55-13: 10$ & $17: 55-18: 10$ \\
\hline Sedan & 304 & 150 & 154 & 42 & 146 & 147 \\
\hline Suv & 55 & 37 & 42 & 7 & 50 & 41 \\
\hline Pick-ups & 60 & 48 & 47 & 30 & 49 & 50 \\
\hline Buses & 5 & 7 & 5 & 3 & 9 & 7 \\
\hline Trucks & 8 & 4 & 14 & 7 & 6 & 3 \\
\hline Motocycles & 12 & 7 & 11 & 1 & 4 & 25 \\
\hline Total & 444 & 253 & 273 & 90 & 264 & 273 \\
\hline
\end{tabular}


TABLE 2. Sampling points 2

\begin{tabular}{|c|c|c|c|c|c|c|}
\hline \multirow{2}{*}{ Vehicle type } & \multicolumn{3}{|c|}{ Tuesday, 21 ${ }^{\text {st }}$ November } & \multicolumn{3}{c|}{ Saturday, 28 ${ }^{\text {th }}$ October } \\
\cline { 2 - 7 } & $6: 55-7: 10$ & $12: 55-13: 10$ & $17: 55-18: 10$ & $6: 55-7: 10$ & $12: 55-13: 10$ & $\begin{array}{c}17: 55- \\
-18: 10\end{array}$ \\
\hline Sedan & 81 & 96 & 67 & 71 & 91 & 103 \\
\hline Suv & 25 & 43 & 17 & 14 & 17 & 30 \\
\hline Pick-up & 37 & 42 & 42 & 44 & 22 & 36 \\
\hline Buses & 5 & 5 & 4 & 9 & 4 & 4 \\
\hline Trucks & 1 & 5 & 4 & 6 & 8 & 2 \\
\hline Motocycles & 2 & 3 & 7 & 6 & 8 & 4 \\
\hline Total & 151 & 194 & 141 & 150 & 150 & 179 \\
\hline
\end{tabular}

On Tuesday, $21^{\text {st }}$ November, the hour of greatest vehicular traffic was in the morning schedule, while on Saturday, $28^{\text {th }}$ October, the schedule with the highest vehicular traffic was in the afternoon schedule. In both cases, the sedan-type vehicle had the highest incidence (Table 3). walk coming from the city center to the UNACH. Simulation through PTV VISSIM. The results corresponding to the gauges, allowed to design a model similar to that indicated in Figure 1 with the characteristics of vehicular and pedestrian behavior within the domain. Being

TABLE 3. Sampling point 3

\begin{tabular}{|c|c|c|c|c|c|c|}
\hline \multirow{2}{*}{ Vehicle type } & \multicolumn{3}{|c|}{ Tuesday, $21^{\text {st }}$ November } & \multicolumn{3}{c|}{ Saturday, 28 ${ }^{\text {th }}$ October } \\
\cline { 2 - 7 } & $6: 55-7: 10$ & $12: 55-13: 10$ & $17: 55-18: 10$ & $6: 55-7: 10$ & $12: 55-13: 10$ & $17: 55-18: 10$ \\
\hline Sedan & 54 & 12 & 12 & 1 & 10 & 10 \\
\hline Suv & 5 & 9 & 3 & 0 & 3 & 3 \\
\hline Pick-up & 8 & 2 & 1 & 0 & 3 & 1 \\
\hline Autobuses & 0 & 1 & 0 & 0 & 0 & 0 \\
\hline Trucks & 1 & 1 & 0 & 0 & 0 & 0 \\
\hline Motocycles & 1 & 1 & 1 & 0 & 0 & 0 \\
\hline Total & 69 & 26 & 17 & 1 & 16 & 14 \\
\hline
\end{tabular}

Based on a comparative analysis between the days of pedestrian capacity, Tuesday and Saturday, the final result was that, on Tuesday afternoon there was a higher incidence of pedestrians (Table 4), mainly due to the students' entry into their academic activities (Mishra \& Goyal, 2014). The route with the highest pedestrian attendance was the side- a simulation tool, it allows to establish a relationship between the presence of vehicles and the concentration of $\mathrm{NO}_{2}$ (Bahmankhah \& Coelho, 2017).

PTV VISSIM allowed the assembly of satellite images, on which it was possible to design the vehicular and pedestrian areas, roads, sidewalks, at the same time it was necessary to introduce the 
TABLE 4. Pedestrian counting results

\begin{tabular}{|c|c|c|c|c|c|c|}
\hline \multirow{2}{*}{ Gauging point } & \multicolumn{3}{|c|}{ Tuesday, 21 ${ }^{\text {st }}$ November } & \multicolumn{3}{c|}{ Saturday, 28 ${ }^{\text {th }}$ October } \\
\cline { 2 - 7 } & $6: 55-7: 10$ & $12: 55-13: 10$ & $17: 55-18: 10$ & $6: 55-7: 10$ & $12: 55-13: 10$ & $17: 55-18: 10$ \\
\hline Point P1 & 251 & 282 & 169 & 6 & 12 & 3 \\
\hline Point P2 & 44 & 79 & 10 & 1 & 2 & 0 \\
\hline Point P3 & 217 & 46 & 46 & 10 & 0 & 4 \\
\hline Point P4 & 13 & 156 & 72 & 5 & 7 & 2 \\
\hline Point P5 & 62 & 60 & 41 & 16 & 7 & 1 \\
\hline
\end{tabular}

information generated from the counting campaigns to allow the software to simulate the behavior of these parameters (Sadat, 2017).

As shown in Figure 2, as the simulation develops the interactions between vehicles are more evident (Yao et al., 2015) it is possible to identify an accumulation of these in front of the entrance to the campus, situation that could be related to the concentration of $\mathrm{NO}_{2}$.

The results generated after the simulation have computer features that were easily recognized by EnVIVER software. By means of an interpolation between emission factors (Margreiter, Krause, Twaddle \& Lüßmann, 2014) established according to the type of vehicle, type of fuel, circulation speed graphs the behav- ior of the $\mathrm{NO}_{2}$ gas in the area of the domain and based on the data generated by PTV VISSIM know that the presence of the gas according to the schedule (higher: Tuesday 7:00, lower: Saturday 7:00) (Sanchez et al., 2017). The area generated by EnVIVER software in front of the main entrance of the campus. The highest concentrations are generated in the circle due to the greater vehicular accumulation in the area.

In order to corroborate the information generated by the models, an experimental campaign was carried out to implement environmental liabilities for the determination of the ambient $\mathrm{NO}_{2}$ concentration (Ji, Bai \& Crocker, 2015), it was propitious to determine the height of the same, and by means of a test carried

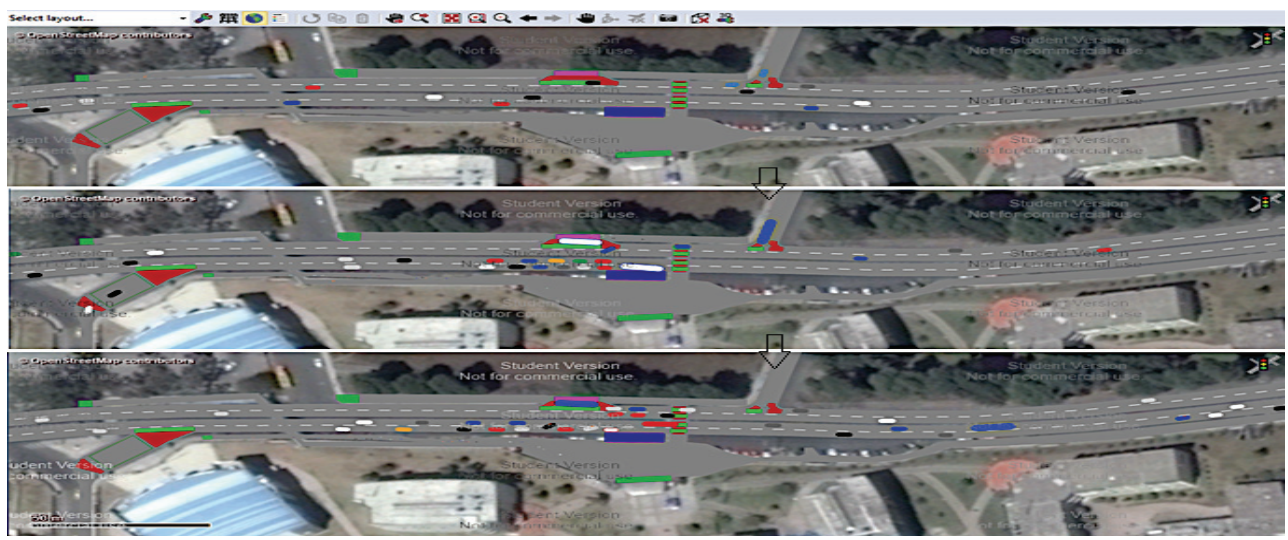

FIGURE 2. Interface, PTV VISSIM, entry of vehicular and pedestrian data 
out at the entrance to the east parking lot of the Edison Riera Rodríguez campus of the UNACH. The result was that the environmental liability with the best catchment results was located at a height of $2 \mathrm{~m}$.

\section{Calibration curve}

It is essential to perform the calibration curve. This method is widely used in analytical chemistry to determine the concentration of a gas in a sample. In this case triethanolamine is important because the solution measures the absorbance and by the calibration curve it is possible to determine the concentration of $\mathrm{NO}_{2}$.

According to the value expressed by $R^{2}$ (Fig. 3), this being greater than 0.95 , the calibration curve is accepted (Kumar et al., 2018), and the equation that allows the calculation of the concentration of each environmental liability exposed in the study domain.

\section{Concentration of $\mathrm{NO}_{\mathrm{x}}$ in exposed environmental liabilities}

After the exposure period, 27 environmental liabilities were analyzed in the spectrophotometer obtaining the following information: out of a total (27) six are exposed, the same ones that frame two values of higher concentration, two values of average concentration and two values of low concentration. Values of $\mathrm{NO}_{\mathrm{x}}$ concentration obtained vary between 1.217 and 0.209 (Table 5).

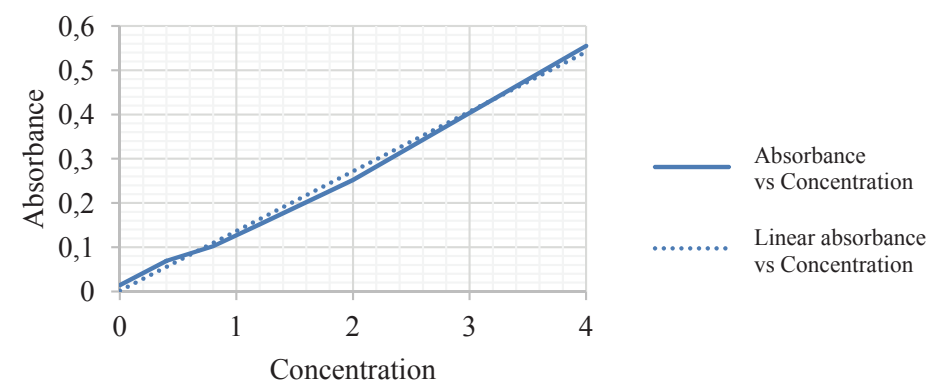

FIGURE 3. Calibration curve of $\mathrm{NO}_{2}$

TABLE 5. Concentration of $\mathrm{NO}_{\mathrm{x}}$

\begin{tabular}{|c|c|c|c|c|}
\hline \multirow{2}{*}{ Liability } & \multicolumn{2}{|c|}{ Coordinates } & \multirow{2}{*}{$\begin{array}{c}\text { Absorbance } \\
{[\mathrm{nm}]}\end{array}$} & $\begin{array}{c}\text { Concentration of } \\
\mathrm{NO}_{\mathrm{x}}\left[\mu \mathrm{g} \cdot \mathrm{ml}{ }^{-1}\right]\end{array}$ \\
\cline { 2 - 3 } & 762078.18 & 9817065.51 & 0.166 & 1.217 \\
\hline 3 & 762109.89 & 9817150.88 & 0.152 & 1.113 \\
\hline 25 & 762183.45 & 9817230.56 & 0.076 & 0.550 \\
\hline 14 & 762214.79 & 9817361.26 & 0.072 & 0.520 \\
\hline 19 & 762089.89 & 9817081.41 & 0.046 & 0.328 \\
\hline 6 & 762179.21 & 9817208.97 & 0.030 & 0.209 \\
\hline
\end{tabular}




\section{Concentration of ambient $\mathrm{NO}_{2}$}

The concentration of nitrites obtained in the previous section allowed to generate values corresponding to the mass of nitrite captured within each environmental passive and in turn the concentration of ambient $\mathrm{NO}_{2}$.

Values of ambient $\mathrm{NO}_{2}$ concentration fluctuate between 12.283 and 2.109 $\mu \mathrm{g} \cdot \mathrm{m}^{-3}$ (Table 6 ), being the result of $156-$ -hour exposure of environmental liabilities at a $2 \mathrm{~m}$ height throughout the study domain with a constant vehicular flow. The liability located in point 3 shows the highest concentration due to its location at the entrance to the university, where the vehicles stop and congestion is generated in the area, producing higher $\mathrm{NO}_{2}$ emissions (Guo et al., 2016).

\section{Generation of concentration maps}

After obtaining the concentration of ambient $\mathrm{NO}_{2}$, geographic information systems were used in order to process the information of each passive and interpolate it throughout the domain. The concentration of ambient $\mathrm{NO}_{2}$ distributed throughout the domain shows that the section of track with direction the UNACH - center, maintains higher concentrations. For this reason, pedestrians using the sidewalk located in this area are exposed to them.

\section{PTV VISSIM simulation}

After processing the information generated in the simulation, it was possible to predict the areas with the highest

TABLE 6. Concentration of ambient $\mathrm{NO}_{2}$

\begin{tabular}{|c|c|c|c|}
\hline Liability & $\begin{array}{c}\text { Concentration } \\
{\left[\mu \mathrm{g} \cdot \mathrm{ml}^{-1}\right]}\end{array}$ & $\begin{array}{c}\text { Nitrite mass } \\
{[\mu \mathrm{g}]}\end{array}$ & $\begin{array}{c}\text { Concentration of ambient } \\
\mathrm{NO}_{2} \\
{\left[\mu \mathrm{g} \cdot \mathrm{m}^{-3}\right]}\end{array}$ \\
\hline 3 & 1.220 & 3.650 & 12.283 \\
\hline 25 & 1.113 & 3.340 & 11.236 \\
\hline 14 & 0.550 & 1.650 & 5.550 \\
\hline 19 & 0.520 & 1.561 & 5.251 \\
\hline 6 & 0.328 & 0.983 & 3.306 \\
\hline 13 & 0.209 & 0.627 & 2.109 \\
\hline
\end{tabular}

\section{Maximum allowed limit}

When comparing the concentrations of ambient $\mathrm{NO}_{2}$, for the liabilities with the high, low and intermediate values of said concentration, it is observed that they remain below the maximum allowable of $40 \mu \mathrm{g} \cdot \mathrm{m}^{-3}$ (WHO, 2018). Up to 28 units below the highest recorded concentration and to 38 units below at the lowest recorded concentration, as shown in Figure 4. concentration based on vehicular behavior, thus obtaining a $\mathrm{NO}_{\mathrm{x}}$ concentration map (Fig. 5). The prediction made by PTV VISSIM and expressed through a map of $\mathrm{NO}_{\mathrm{x}}$ concentration is similar to the map generated after the interpolation of the results of each environmental passive, allowing to corroborate the reliability of both processes. 


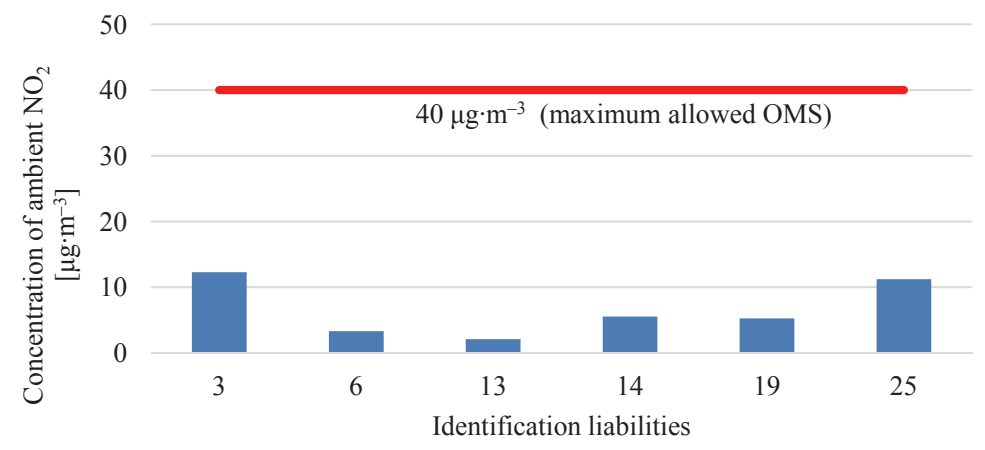

FIGURE 4. Comparison between average and maximum allowed concentrations
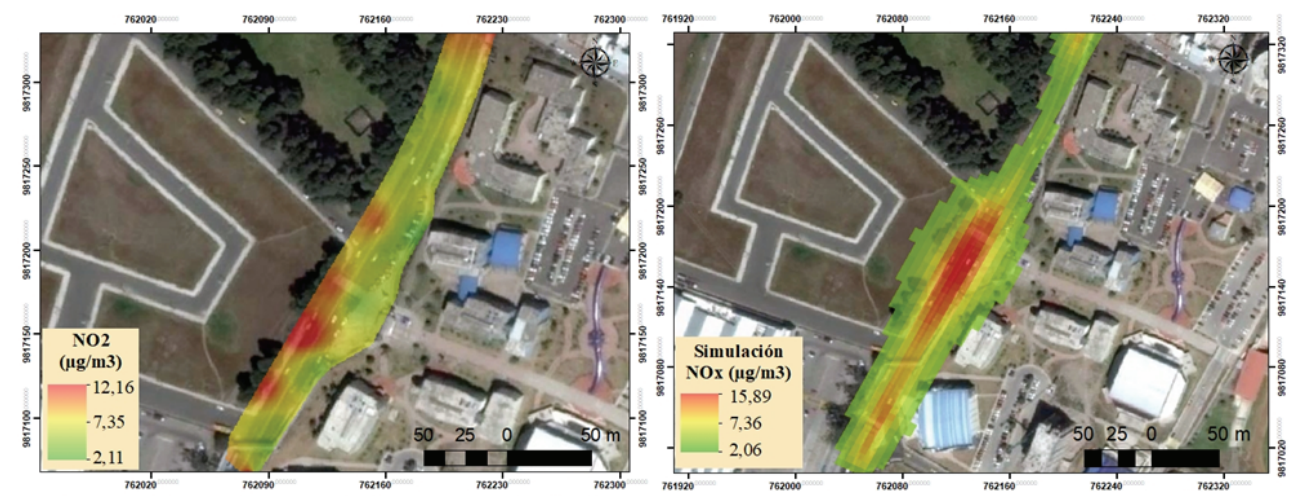

FIGURE 5. Concentration of $\mathrm{NO}_{\mathrm{x}}$ modeled, concentration of ambient $\mathrm{NO}_{2}$

\section{Conclusions}

The results presented show the versatility and usefulness of passive monitoring for the quantification of atmospheric gas concentrations, in this case, $\mathrm{NO}_{2}$, in the different monitoring stations. Through the use of $\mathrm{NO}_{2}$ sensors to determine the concentration in the study area, it was possible to determine the existing variation according to the points at which the environmental liabilities were located. Evidencing a fluctuation of $\mathrm{NO}_{2}$ concentrations ranging from 0.209 to $1.22 \mu \mathrm{g} \cdot \mathrm{ml}^{-1}$. The maximum concentration of $\mathrm{NO}_{2}$ that was obtained generated a value of $12.38 \mu \mathrm{g} \cdot \mathrm{m}^{-3}$, this value is below the permissible limits, in such a way that it is possible to determine that it does not significantly affect the air quality in the area of study accord to Tang et al. (2016). Considering the results obtained, we mention the highest value of $\mathrm{NO}_{2}$ ambient concentration which is considered optimal for the passers-by's breathing, that is to say that it does not generate a greater risk when in contact with it. This value comes from the samplings made with the environmental passives in different points, $12.38 \mu \mathrm{g} \cdot \mathrm{m}^{-3}$, the same one that is below the permissible limits, which determines that it is totally adequate and breathable. Technological tools such as PTV VISSIM, 
PTV VISWALK and GIS made it possible to determine that on the pavement with the city of Guano to the city of Riobamba direction the concentrations are clearly accentuated in relation to the avenue with Riobamba to Guano direction, due to the acceleration and deceleration of vehicles since here there is a variation in the combustion processes of vehicles according with Chen et al. (2018). When the vehicle decelerates, it emits a greater amount of $\mathrm{NO}_{2}$ and when it accelerates, the amount of gas emission decreases.

\section{References}

Bahmankhah, B. \& Coelho, M.C. (2017). Multi-objective optimization for short distance trips in an urban area: choosing between motor vehicle or cycling mobility for a safe, smooth and less polluted route. Transportation Research Procedia, 27, 428-435. https:// doi.org/10.1016/J.TRPRO.2017.12.009

Borge, R., Narros, A., Artíñano, B., Yagüe, C., Gómez-Moreno, F.J., de la Paz, D., ... Vardoulakis, S. (2016). Assessment of microscale spatio-temporal variation of air pollution at an urban hotspot in Madrid (Spain) through an extensive field campaign. Atmospheric Environment, 140, 432-445. https://doi. org/10.1016/J.ATMOSENV.2016.06.020

Borge, R., Quaassdorff, C., Paz, D. de la, Narros, A., Paredes, M. \& Andres, J. de. (2015). Experimental Campaing in a Heavily Trafficked Roundabout in Madrid for the Assessment of Air Quaity Monitoring Station Representativeness in Terms of Population Exposure to $\mathrm{NO}_{2}$. In 2nd Healthy Polis Workshop-during Kunshan Forum. Retrieved from https://www. researchgate.net/publication/315078458 Experimental_Campaign_in_a_Heavily_Trafficked_Roundabout_in_Madrid_for_the Assessment_of_Air_Quality_Monitoring Station_Representativeness_in_Terms_of_Population_Exposure_to_ $\mathrm{NO}_{2}$

Chen, H., Xie, B., Ma, J. \& Chen, Y. (2018). NOx emission of biodiesel compared to diesel:
Higher or lower? Applied Thermal Engineering, 137, 584-593. https://doi.org/10.1016/ J.APPLTHERMALENG.2018.04.022

El Morabet, R. (2019). Effects of Outdoor Air Pollution on Human Health. Reference Module in Earth Systems and Environmental Sciences. https://doi.org/10.1016/B978-0-12409548-9.11509-X

Glarborg, P., Miller, J.A., Ruscic, B. \& Klippenstein, S.J. (2018). Modeling nitrogen chemistry in combustion. Progress in Energy and Combustion Science, 67, 31-68. https://doi. org/10.1016/J.PECS.2018.01.002

Grundström, M., Hak, C., Chen, D., Hallquist, M. \& Pleijel, H. (2015). Variation and co-variation of PM10, particle number concentration, $\mathrm{NO}_{\mathrm{x}}$ and $\mathrm{NO}_{2}$ in the urban air - Relationships with wind speed, vertical temperature gradient and weather type. Atmospheric Environment, 120, 317-327. https://doi. org/10.1016/J.ATMOSENV.2015.08.057

Guo, X., Fu, L., Ji, M., Lang, J., Chen, D. \& Cheng, S. (2016). Scenario analysis to vehicular emission reduction in Beijing-Tianjin-Hebei (BTH) region, China. Environmental Pollution, 216, 470-479. https://doi.org/10.1016/ J.ENVPOL.2016.05.082

Jaikumar, R., Shiva Nagendra, S.M. \& Sivanandan, R. (2017). Modal analysis of real-time, real world vehicular exhaust emissions under heterogeneous traffic conditions. Transportation Research Part D: Transport and Environment, 54, 397-409. https://doi. org/10.1016/J.TRD.2017.06.015

Ji, Y., Bai, S. \& Crocker, M. (2015). $\mathrm{Al}_{2} \mathrm{O}_{3}$-based passive NOx adsorbers for low temperature applications. Applied Catalysis B: Environmental, 170-171, 283-292. https://doi. org/10.1016/J.APCATB.2015.01.025

Kumar, M., Tsujimura, T. \& Suzuki, Y. (2018). NOx model development and validation with diesel and hydrogen/diesel dual-fuel system on diesel engine. Energy, 145, 496-506. https://doi.org/10.1016/j.energy.2017.12.148

Li, P-W., Chyang, C-S. \& Ni, H-W. (2018). An experimental study of the effect of nitrogen origin on the formation and reduction of NOx in fluidized-bed combustion. Energy, 154, 319-327. https://doi.org/10.1016/ J.ENERGY.2018.04.141 
Margreiter, M., Krause, S., Twaddle, H. \& Lüßmann, J. (2014). Evaluation of Environmental Impacts of Adaptive Network Signal Controls Based on Real Vehicle Trajectories. Transportation Research Procedia, 4, 421-430. https://doi.org/10.1016/ J.TRPRO.2014.11.032

Mishra, D. \& Goyal, P. (2014). Estimation of vehicular emissions using dynamic emission factors: A case study of Delhi, India. Atmospheric Environment, 98, 1-7. https://doi. org/10.1016/j.atmosenv.2014.08.047

Nakashima, Y., Sadanaga, Y., Saito, S., Hoshi, J. \& Ueno, H. (2017). Contributions of vehicular emissions and secondary formation to nitrous acid concentrations in ambient urban air in Tokyo in the winter. Science of The Total Environment, 592, 178-186. https://doi. org/10.1016/J.SCITOTENV.2017.03.122

Nhung, N.T.T., Schindler, C., Dien, T.M., Probst-Hensch, N., Perez, L. \& Künzli, N. (2018). Acute effects of ambient air pollution on lower respiratory infections in Hanoi children: An eight-year time series study. Environment International, 110, 139-148. https://doi. org/10.1016/J.ENVINT.2017.10.024

Park, S. \& Hwang, K. (2017). Experimental Analysis on control constraints for connected vehicles using Vissim. Transportation Research Procedia, 21, 269-280. https://doi. org/10.1016/J.TRPRO.2017.03.097

Rahmati, M.H. \& Yousefi, S.R. (2013). Demand estimation for the Iranian automobile industry. The Quarterly Review of Economics and Finance, 53(3), 277-284. https://doi. org/10.1016/J.QREF.2011.03.001

Sadat, M. (2017). Simulation-based Variable Speed Limit Systems Modelling: An Overview and A Case Study on Istanbul Freeways. Transportation Research Procedia, 22, 607-614. https://doi.org/10.1016/ J.TRPRO.2017.03.051

Sanchez, B., Santiago, J.L., Martilli, A., Martin, F., Borge, R., Quaassdorff, C. \& de la Paz, D. (2017). Modelling NOX concentrations through CFD-RANS in an urban hot-spot using high resolution traffic emissions and meteorology from a mesoscale model. Atmospheric Environment, 163, 155-165. https:// doi.org/10.1016/J.ATMOSENV.2017.05.022
Schraufnagel, D.E., Balmes, J.R., Cowl, C.T., De Matteis, S., Jung, S-H., Mortimer, K., ... Wuebbles, D.J. (2019). Air Pollution and Noncommunicable Diseases: A Review by the Forum of International Respiratory Societies' Environmental Committee, Part 1: The Damaging Effects of Air Pollution. Chest, 155(2), 409-416. https://doi.org/10.1016/ J.CHEST.2018.10.042

Tang, G., Chao, N., Wang, Y. \& Chen, J. (2016). Vehicular emissions in China in 2006 and 2010. Journal of Environmental Sciences, 48, 179-192. https://doi.org/10.1016/ /J.JES.2016.01.031

Villanueva, M. \& Dosal, M,. (2008). Calibration curves in analytical methods. Introduction to Chemical Metrology, 18-26.

World Health Organization [WHO] (2018). Ambient (outdoor) air quality and health.

Yao, Z., Wu, B., Wu, Y., Cao, X. \& Jiang, X. (2015). Comparison of NOx emissions from China III and China IV in-use diesel trucks based on on-road measurements. Atmospheric Environment, 123, 1-8. https://doi. org/10.1016/J.ATMOSENV.2015.10.056

\section{Summary}

Determining $\mathrm{NO}_{2}$ immission levels in a conflicted area: Riobamba, Ecuador. Riobamba has areas with high vehicular influence. For the determination of nitrogen dioxide concentrations, passive samplers were used, which were placed at points throughout the domain. The concentrations obtained in the field were interpolated with the information generated with the model traffic emissions software, estimating the relationship between vehicular traffic and the presence of gas. Allow to know the amount of pollutants that breathe about 250 pedestrians on average in the area.

\section{Authors' address:}

Marcel Paredes

(https://orcid.org/0000-0002-3762-9633)

National University of Chimborazo

Faculty of Engineering

Av. Antonio José de Sucre, Km 11⁄2, 060150

Riobamba

Ecuador

e-mail: marcelparedes@unach.edu.ec 